\title{
Power Quality Aspects in a Wind Power Plant
}

Conference Paper NREL/CP-500-39183 January 2006

\section{Preprint}

E. Muljadi and C.P. Butterfield

National Renewable Energy Laboratory

J. Chacon

Southern California Edison

H. Romanowitz

Oak Creek Energy Systems, Inc.

To be presented at the IEEE Power Engineering Society General Meeting

Montreal, Quebec, Canada

June 18-22, 2006 


\section{NOTICE}

The submitted manuscript has been offered by an employee of the Midwest Research Institute (MRI), a contractor of the US Government under Contract No. DE-AC36-99G010337. Accordingly, the US Government and MRI retain a nonexclusive royalty-free license to publish or reproduce the published form of this contribution, or allow others to do so, for US Government purposes.

This report was prepared as an account of work sponsored by an agency of the United States government. Neither the United States government nor any agency thereof, nor any of their employees, makes any warranty, express or implied, or assumes any legal liability or responsibility for the accuracy, completeness, or usefulness of any information, apparatus, product, or process disclosed, or represents that its use would not infringe privately owned rights. Reference herein to any specific commercial product, process, or service by trade name, trademark, manufacturer, or otherwise does not necessarily constitute or imply its endorsement, recommendation, or favoring by the United States government or any agency thereof. The views and opinions of authors expressed herein do not necessarily state or reflect those of the United States government or any agency thereof.

Available electronically at http://www.osti.gov/bridge

Available for a processing fee to U.S. Department of Energy and its contractors, in paper, from:

U.S. Department of Energy

Office of Scientific and Technical Information

P.O. Box 62

Oak Ridge, TN 37831-0062

phone: 865.576.8401

fax: 865.576 .5728

email: mailto:reports@adonis.osti.gov

Available for sale to the public, in paper, from:

U.S. Department of Commerce

National Technical Information Service

5285 Port Royal Road

Springfield, VA 22161

phone: 800.553 .6847

fax: 703.605.6900

email: orders@ntis.fedworld.gov

online ordering: http://www.ntis.gov/ordering.htm 


\section{POWER QUALITY ASPECTS IN A WIND POWER PLANT}

\author{
E. Muljadi ${ }^{1}$ \\ ${ }^{1}$ National Renewable Energy Laboratory \\ 1617 Cole Blvd. \\ Golden, CO 80401
}

\author{
J. Chacon ${ }^{2}$ \\ ${ }^{2)}$ Southern California Edison \\ P.O. Box 800 \\ Rosemead, CA 91770
}

\author{
H. Romanowitz $z^{3}$ \\ ${ }^{3)}$ Oak Creek Energy Systems Inc. \\ 14633 Willow Springs Rd. \\ Mojave, CA 93501
}

\begin{abstract}
Like conventional power plants, wind power plants must provide the power quality required to ensure the stability and reliability of the power system it is connected to and to satisfy the customers connected to the same grid. When wind energy development began, wind power plants were very small, ranging in size from under one megawatt to tens megawatts with less than 100 turbines in each plant. Thus, the impact of wind power plant on the grid was very small, and any disturbance within or created by the plant was considered to be in the noise level.
\end{abstract}

In the past 30 years, the size of wind turbines and the size of wind power plants have increased significantly. Notably, in Tehachapi, California, the amount of wind power generation has surpassed the infrastructure for which it was designed. At the same time, the lack of rules, standards, and regulations during early wind development has proven to be an increasing threat to the stability and power quality of the grid connected to a wind power plant.

Fortunately, many new wind power plants are equipped with state of the art technology, which enables them to provide good service while producing clean power for the grid. The advances in power electronics have allowed many power system applications to become more flexible and to accomplish smoother regulation. Applications such as reactive power compensation, static transfer switches, energy storage, and variable-speed generations are commonly found in modern wind power plants.

Although many operational aspects affect wind power plant operation, this paper, focuses on power quality. Because a wind power plant is connected to the grid, it is very important to understand the sources of disturbances that affect the power quality. In general, the voltage and frequency must be kept as stable as possible. The voltage and current distortions created by harmonics will also be discussed in this paper as will self-excitation, which may occur in a wind power plant due to loss of line.

Index Terms - wind turbine, wind farm, wind power plant, power quality, wind energy, aggregation, power systems, renewable energy, reactive power compensation, self-excitation, harmonics.

\section{INTRODUCTION}

In the past 30 years, the size of wind power plants has increased significantly. Notably, in Tehachapi, California, the amount of wind power generation has surpassed the capability of the infrastructure for which it was designed. The infrastructure was built to support small, scattered wind generation. Similarly, because wind plants were so small in the past, the rules governing wind generation were more relaxed to encourage development. For example, in the past, wind turbines were only required to have capacitor compensation at each turbine to satisfy the no-load reactive power generation. But as the amount of wind generation increases, the lack of rules, standards, and regulations during early wind development has proven to be an increasing threat to the stability and power quality of the interconnected grid.

Although many operational aspects affect wind power plant operation, in this paper, we focus on power quality. Because a wind power plant is connected to the grid, it is very important to understand the sources of disturbances that affect its power quality. In general, the voltage and frequency must be kept as stable as possible; therefore, voltage and current distortions created by harmonics will also be discussed in this paper. Selfexcitation, which may occur in a wind power plant due to loss of line, will also be presented.

Section II describes the voltage and frequency variations, and Section III discusses single and multiple turbines representation. Section IV presents harmonics and self-excitation, and Section V presents the summary.

We used Power Systems Simulation for Engineers $\left(\mathrm{PSSE}^{\mathrm{TM}}\right.$ ) from Siemens Power Technologies Inc., and Visual Simulation (Vissim) from Visual Solution Inc.

\section{VOLTAGE AND FREQUENCY VARIATIONS}

\section{A. Overview}

This section describes the interaction between the wind power plant, reactive power compensation, and the power system network. The Tehachapi power system network used in this study is based on a power system diagram from 1999 [1]. Thus, the simulation results 
presented in this paper do not necessarily reflect the current situation. The current power system network has been improved to accommodate more wind power generation.

Because the loads and the wind power plants' output fluctuate during the day, the use of reactive power compensation is ideal for maintaining normal voltage levels in the power system network. Reactive power compensation can minimize reactive power imbalances that can affect the surrounding power system.

In this section, we will show how the contribution of wind power plants affects the power distribution network and how the power distribution network and reactive power compensation interact when the wind changes.

About 24 wind power plants are included in the simulation. The wind power plants represent 1- to 70MW wind power plants. The wind power plants are connected to the rest of the transmission network. Bus 1, which is Antelope Substation, is used as the gateway to the much larger network outside the area and is treated as an infinite bus. Each wind power plant represents the following characteristics:

1. The characteristics of the wind resource (turbulence level, average speed, air density, etc.).

2. Diversity of the wind speeds with respect to the locations of each wind power plant in the Tehachapi area. For a more detailed discussion on simulation of wind power plant aggregation, see reference [2].

3 . The characteristics of the wind turbine $(\mathrm{Cp}-\mathrm{TSR}$ characteristics) and induction generator

4.The P-Q (real and reactive power) electrical characteristic of the individual wind power plants.

When the work presented in this paper was developed, no wind turbine or wind power plant models were commercially available, thus, the model presented here was developed at NREL. Today many wind turbine models are commercially available and can be downloaded from the GE website, the Siemens Power Technologies International website, and other software vendors.

\section{B. Voltage Variation}

This section presents the voltage variations caused by the wind speed changes and a comparison between an uncompensated and a compensated system. The term compensated refers to the use of static reactive power compensation to improve the voltage characteristics of the wind power plant. The CalCement substation (bus 22) has 18 MVAR capacitor compensation installed. Other buses in the area are compensated to a total of 77.3 MVAR. The total load in the area (including surrounding small towns) is about $259 \mathrm{MW}$ and 46.4
MVAR. The generations at Kern River and Bailey are $24 \mathrm{MW}$ and $20 \mathrm{MW}$, respectively. The simulation was fed by non-uniform wind speeds to simulate the entire area. A total simulation time of 6000 seconds (100 minutes) is used to cover the spectrum of possible wind fluctuations. For a wind power plant power system, IEC Standard 61400-21 stated that the 10-minute average of voltage fluctuation should be within $\pm 5 \%$ of its nominal value [3].

A typical reactive power compensator may be implemented by using a fixed capacitor, a switched capacitor, or static compensator [4-5]. The simplest form of reactive power compensation is the static VAR compensator (SVC). By choosing the correct size of inductor and capacitor, the SVC can be operated to generate reactive power, which varies from - $\mathrm{Q}_{\text {lolim }}$ to + Qhilim. For example, with a 100-MVAR capacitor and a 200 -MVAR inductor, a range of \pm 100 MVAR can be achieved and adjusted continuously. If negative reactive power is not required, a combination of a 100-MVAR

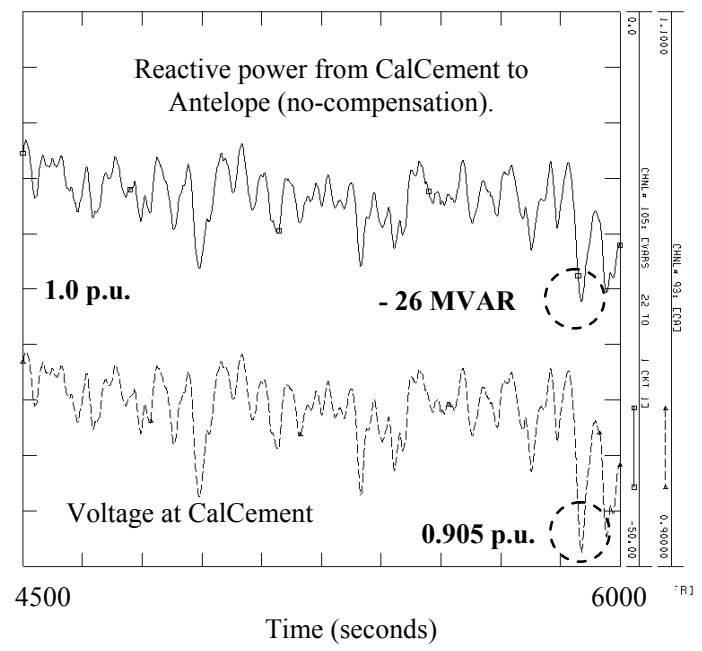

Figure 1. Reactive power from bus 22 to bus 1, and voltage at bus 22 without reactive power compensation.

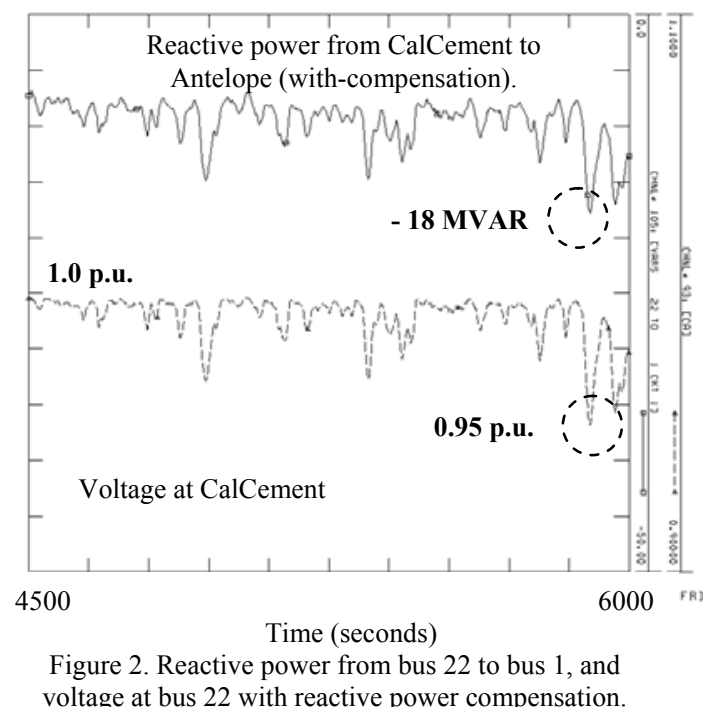


capacitor and a 100-MVAR inductor provides a range of 0 MVAR to +100 MVAR

The reactive power compensation is located inside the wind power plant at VarWind, bus 40 . Figures 1 and 2 compare an uncompensated wind power plant and a compensated wind power plant. Without reactive power compensation, the voltage variation at CalCement (bus 22) drops to 0.905 p.u., and with proper compensation, the voltage drops to 0.95 p.u., which is considered allowable for a wind power plant. Note, that the reactive power flows from the Antelope drops significantly (from 26 MVAR to 18 MVAR) when the reactive power is compensated locally. Notice that the voltage traces follow the reactive power traces closely and the minimum voltage occurs at the minimum reactive power flowing from CalCement (or maximum reactive power flowing from Antelope to CalCement).

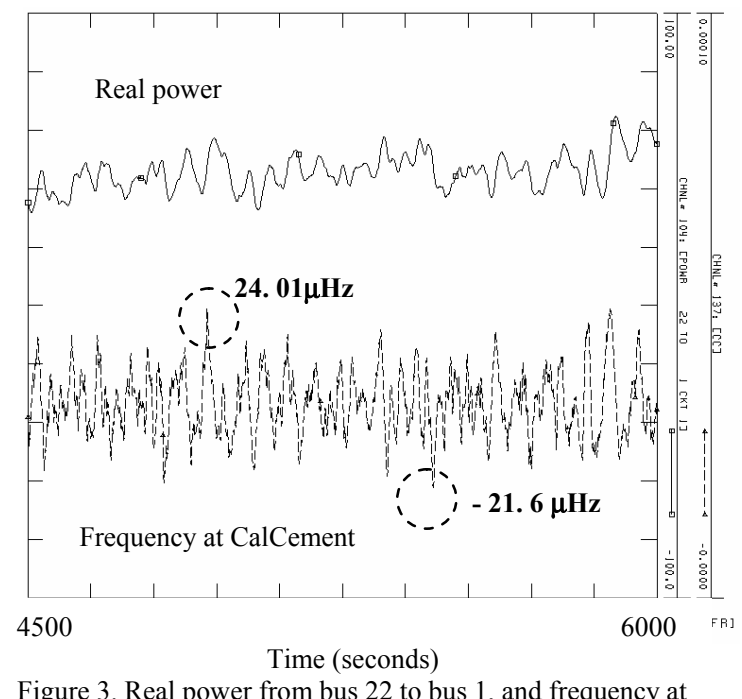
bus 22 without reactive power compensation.

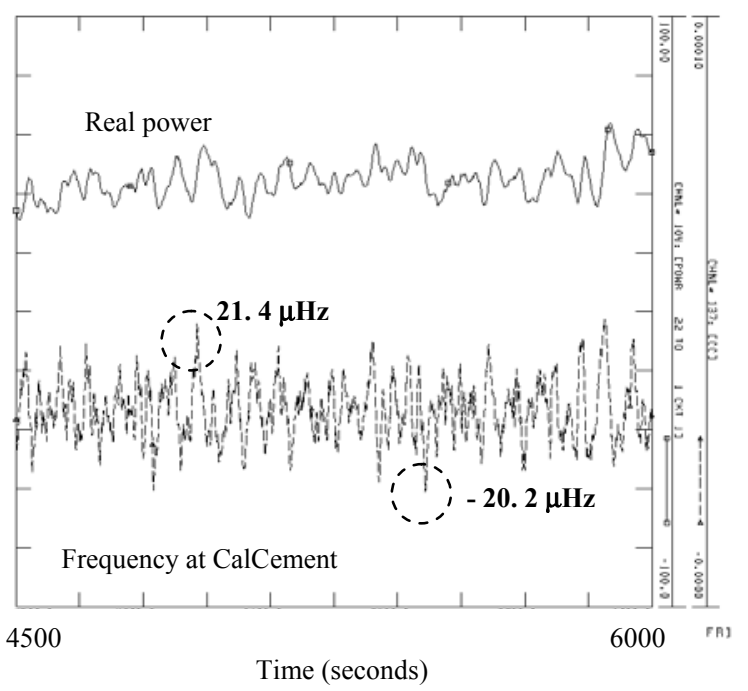

Figure 4. Real power from bus 22 to bus 1 , and frequency at bus 22 with reactive power compensation.

\section{Frequency Variation}

Frequency variation is affected by the rate of change in real power flow. Thus, there is a difference in the trend between the voltage-reactive power traces compared to frequency-real power traces relationship. The reactive power improves the voltage characteristic of the wind power plant and surrounding area. Comparing Figures 3 and 4, the real power flow is not affected by the reactive power compensation. Although the frequency variation is barely noticeable, it indicates that there are differences in the rate-changes in the real power flow between compensated and uncompensated systems. It shows that there is a reduction in the frequency swings; however, because the frequency swing is very small to begin with, it is probably not warranted to claim that the reactive power compensation helps reduce the frequency variations. Note, that the minimum frequency does not occur at the maximum power flow but rather the maximum rate of change of the power flow.

\section{Single Turbine ANd Multiple Turbines}

\section{A. Single Turbine Representation (STR)}

In this section, we look at a wind power plant represented by one group of wind turbines. This is the worst-case assumption because we assume that all the wind turbines in this group are synchronized. Thus, the same wind fluctuations and tower shadow effects will affect the output power of the wind power plant and the power quality at the PCC.

\section{B. Multiple Turbine Representation (MTR)}

In this section, we focus on the aggregation impact on the wind power plant output at the PCC. We use the same wind turbulence intensity and the same impedance of the transmission line. We measured the real and reactive power fluctuations, the voltage fluctuations, and at the PCC of a wind power plant. We quantified the difference in power and voltage fluctuations level if we treat a wind power plant as a single turbine or as multiple groups of turbines. The flicker level measurement can be implemented using design specification in IEC 61000-4-15 [1].

Ideally we would like to model every wind turbine on the wind power plant. Unfortunately, a large wind power plant can have more than 100 wind turbines on site. Therefore, it is not possible to represent all the turbines simultaneously, because the computing time would be excessive. To closely represent a real wind power plant without simulating each wind turbine, we made the following assumptions:

A large wind power plant (200 turbines) is divided into several groups of wind turbines. 
- The wind speed is uniform for each group of wind turbines.

- The groups are arranged in sequence.

- Our interest is in the long-term simulation, thus the start-up of each turbine is not a major concern. Besides, because the wind speeds are different at each turbine location, all the wind turbines do not start at the same time.

- All the turbines in the wind power plant are exposed to of $18.7 \mathrm{~m} / \mathrm{s}$ and turbulence level of $19.7 \%$. The time series wind speed shifts by 1 minute for each group.

- The contribution of each group is chosen randomly. For example, a wind power plant with 3 groups of turbines may be proportioned as $35 \%$ from the first group, $25 \%$ from the second group, and $40 \%$ from the third group.

- This concept of grouping is repeated for different numbers of groups, but the total wind turbines in the entire wind power plant is kept the same-200 turbines.

- Eventually we will compare the impact of wind turbine distribution by comparing the flicker and the voltage fluctuations based on groupings (one group only, two groups, four groups, and eight groups).

\section{Comparison between STR and MTR}

To start, consider the time series of wind speed shown in Figure 5. In an STR, the wind speed is applied to a single turbine and the output of the single wind turbine is multiplied by the number of the turbines within the wind power plant. In an MTR, the time series of the wind speed is subdivided into several sections and each subdivision is applied to a different group of turbines. For example, for the figure shown, the time series of wind speed is divided into four different files with the starting time $(\mathrm{t}=0)$ at $\mathrm{w} 1, \mathrm{w} 2, \mathrm{w} 3$ and $\mathrm{w} 4$. This assumption is an approximation of the time it takes for the wind speed to travel from one group of turbines to another group of turbines down wind. Although this assumption is not perfect, by assuming that the wind speed has a characteristic of frozen turbulence, and that the turbulence does not change as it passes a wind turbine, we can more closely simulate the real situation.

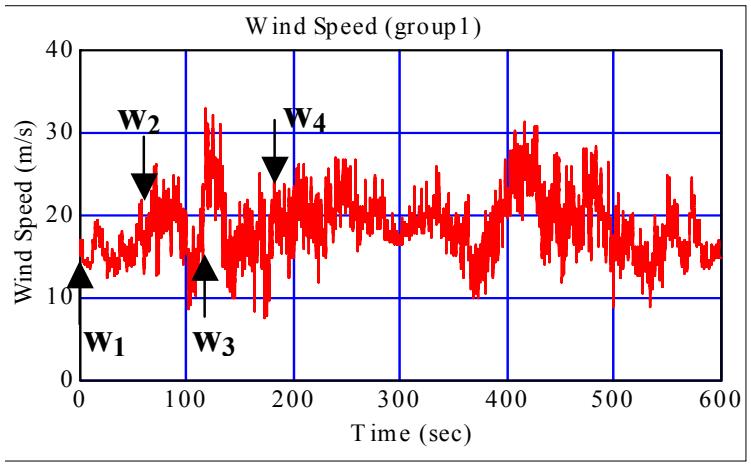

Figure 5. Wind speed variation applied to the wind turbines.
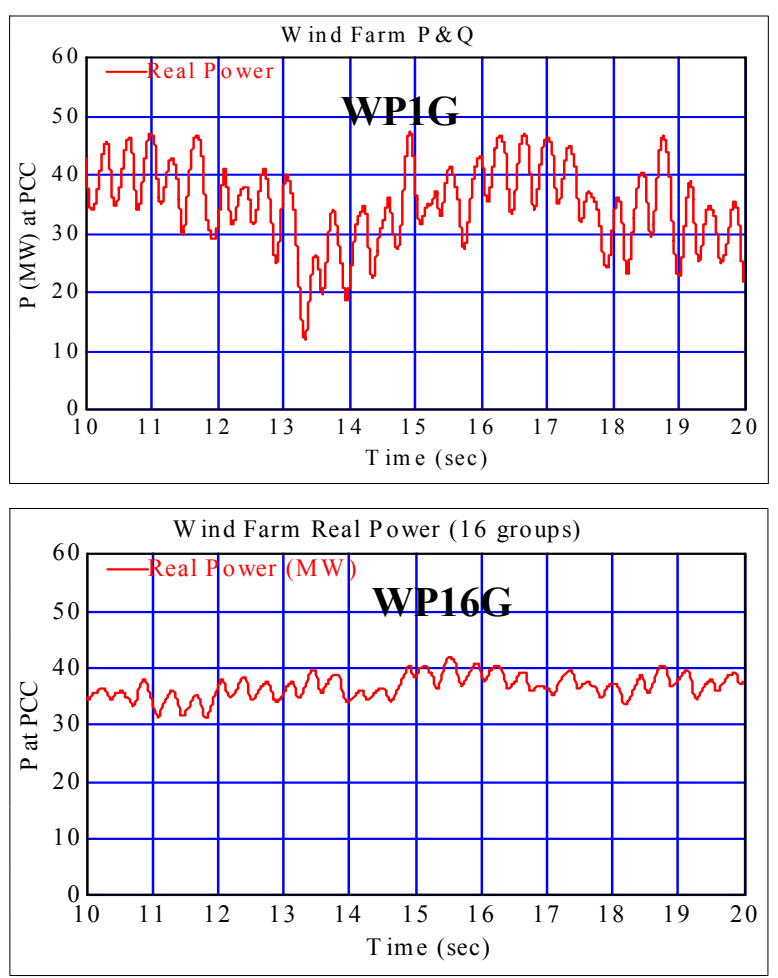

Figure 6. Real power output of a wind farm in a WP1G and in a WP16G.

Let us consider the output of STR and MTR and place the two graphs next to each other for a better comparison. Figure 6 shows variation of real power for both representations taken at the point of interconnection. The time scale is changed to make an easier observation of the nature of power fluctuations within a short time frame. In these particular traces, the trace of tower shadow is very visible. Tower shadow effect is the effect of power fluctuations due to power production deficit every time a blade passes the turbine tower. Usually the tower shadow has a frequency 3 per revolution. This effect is commonly known as $3 \mathrm{p}$ effects. Besides the tower shadow, the power variation is also caused by the wind speed variations with time. For the STR, the power fluctuation reflects the power fluctuation of a single turbine. It is amplified by the number of turbines within the wind power plant. For the MTR, the power fluctuation is the collective behavior of several groups of wind turbines with each group fed by a different time series as illustrated in Figure 5.

The label WP1G is a single-group representation and WP16G is a 16-group representation. Comparing the two graphs, it is obvious that there is some smoothing effect in the power fluctuations if we consider that the wind power plant consists of sixteen different groups of wind turbines. Figure 7 shows the voltage fluctuations as the wind speed varies with two different representations. The STR obviously shows very large variations of the voltage at the point of interconnection as the wind speed 

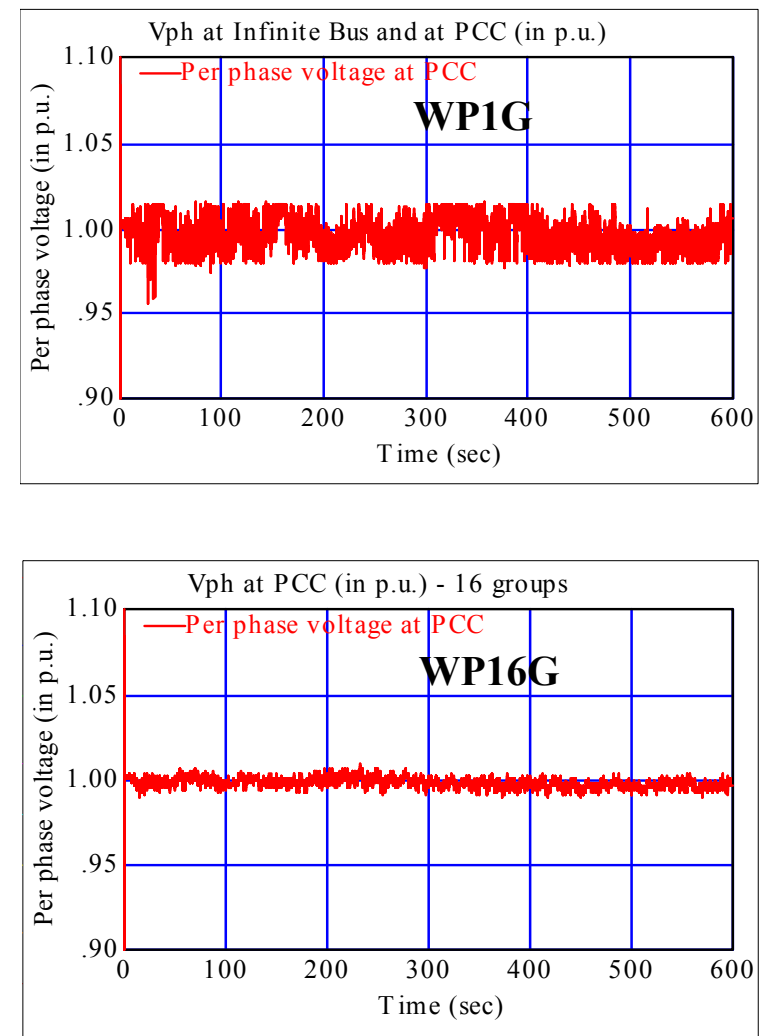

Figure 7. Voltage at the point of interconnection for WG1G and WP16G

varies while the output voltage for 16 groups representation shows a much smaller voltage swings.

\section{SElF EXCITATION AND HARMONICS}

\section{A. Overview}

Traditional wind turbines are equipped with induction generators. Induction generators are preferred, because they are inexpensive, rugged, and require very little maintenance. Unfortunately, induction generators require reactive power from the grid to operate and some capacitor compensations are often used. Because reactive power varies with the output power, the capacitor compensation is adjusted as the output power varies. The interactions among the wind turbine, the power network, and the capacitor compensation (shown in Figure 8) are important aspects of wind generation [6]. In this section, we will show the interactions among the induction generator, capacitor compensation, power system network, and magnetic saturations and examine the cause of self-excitation and harmonic currents.

\section{B. Self Excitation}

Self-excitation can occur in a fixed-speed wind turbine equipped with an induction generator. Fixed capacitors are the most commonly used method of reactive power compensation in a fixed-speed wind turbine. Induction generators alone cannot self excite. It

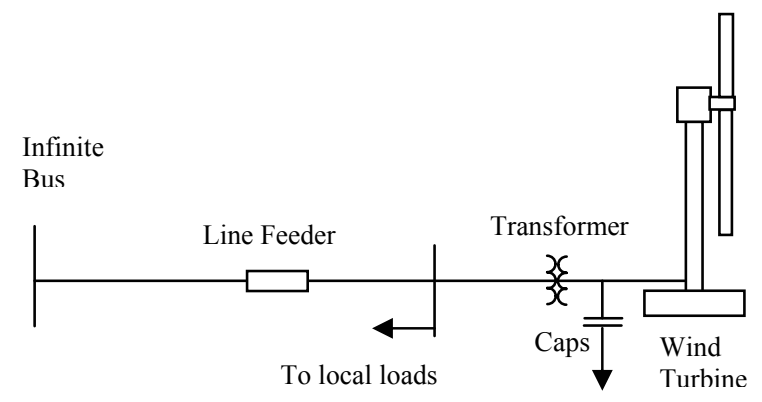

Figure 8 . The physical diagram of the system under investigation.

requires reactive power from the grid to operate normally. The grid dictates the voltage and frequency of the induction generator.

Although self-excitation does not occur during normal grid-connected operation, it can occur during offgrid operation. For example, if a wind turbine operating in normal mode becomes disconnected from the power line due to a sudden fault or disturbance in the line feeder, the capacitors connected to the induction generator will provide reactive power compensation. However, the voltage and the frequency are determined by the balancing of the systems.

One disadvantage to self-excitation is the safety aspect. Because the generator is still generating voltage, it may compromise the safety of the personnel inspecting or repairing the line or generator. Another disadvantage is that the generator's operating voltage and frequency are determined by the balance between the system's real power and the reactive power. Thus, if sensitive equipment is connected to the generator during selfexcitation, the equipment may be subjected to over/under voltage and over/under frequency operation. In spite of the disadvantages of operating the induction generator in self-excitation, some people use selfexcitation for dynamic braking to help control the rotor speed during an emergency such as a grid loss condition. Thus, with the proper choice of capacitance and resistor load (to dump the energy from the wind turbine), the wind turbine can be brought to a safe operating speed during grid loss and mechanical brake malfunctions.

In an isolated operation, the conservation of real and reactive power must be preserved. The equation governing the system can be simplified by looking at the impedance or admittance of the induction machine. To operate in an isolated fashion, the total admittance of the induction machine and the rest of the connected load must be zero. The voltage of the system is determined y the flux and frequency of the system. Thus the level of saturation plays an important role in sustaining or collapsing the self-excitation process. A more detailed description of the self-excitation process in a wind turbine operating off grid can be found in reference [6]. 


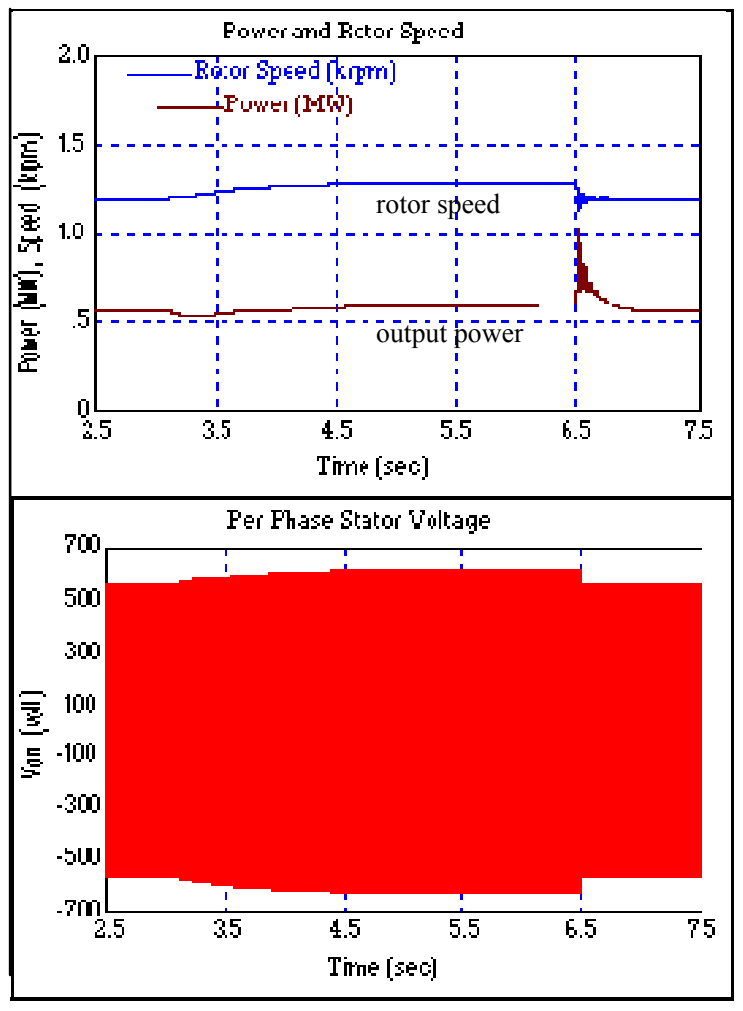

Figure 9. Traces during transient versus the time a) the rotor speed and output power

b) voltage variation during transient

Figure 9 shows traces of rotor speed, output power, and voltage of an induction generator compensated with local capacitors when it was separated from the grid at about $\mathrm{t}=3.1 \mathrm{sec}$, feeding a local load, and reconnected to the grid at $\mathrm{t}=6.5 \mathrm{sec}$. During the transient, the generator output power and rotor speed varies with the induction generator slip, the level of saturation, and the load connected to the island network. The voltage increases by $11 \%$, and the frequency increases by $4.2 \%$. The voltage and frequency settle at the balance of real power and reactive power.

\section{Harmonics}

We replaced the power network, shown in Figure 8, with a per phase equivalent circuit, shown in Figure 10, to represent harmonic components of the circuit. In this circuit representation, the harmonics is denoted with $\mathrm{h}$ to indicate the higher harmonics multiples of $60 \mathrm{~Hz}$. Thus $\mathrm{h}=5$ indicates the fifth harmonics $(300 \mathrm{~Hz})$. In wind turbine applications, the induction generator, transformer, and capacitors are three phases and either Wye or Delta is connected. Thus, the flow of even harmonics, the third, and its multiples do not exist (only $\mathrm{h}=5,7,11,13,17$. . etc.).

1) Infinite Bus and Line Feeder

The infinite bus and the line feeder connecting the wind turbine to the substation are represented by a simple Thevenin representation of the larger power system

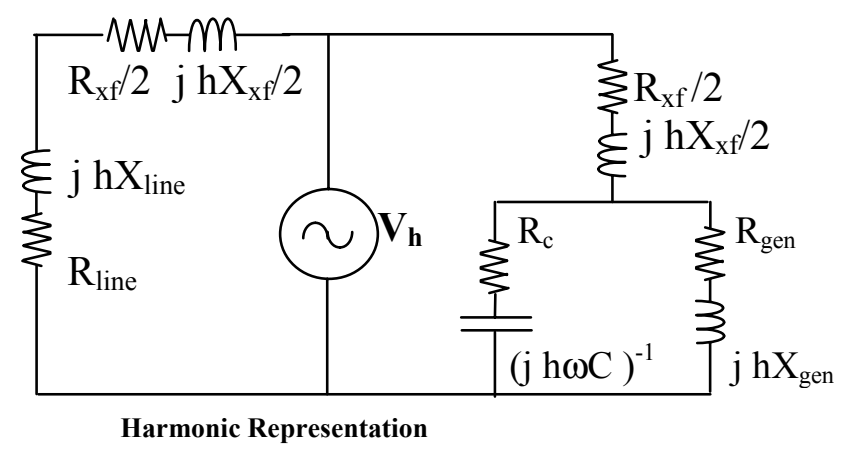

Figure 10. The per phase equivalent circuit of the simplified model for harmonic analysis.

network. Thus, we consider a simple RL line representation.

2) Transformer

We considered a three-phase transformer with standard impedance of $6 \%$. Because the magnetizing inductance of a large transformer is usually very large compared to the leakage inductance, only the leakage inductance will be considered. Assuming the efficiency of the transformer is about $98 \%$ at full load, and the copper loss is equal to the core loss (general assumption for an efficient, large transformer), we can approximate the winding resistance, which is generally very small for an efficient, large transformer.

3) Capacitor Compensation

The capacitors representing the compensation of the wind turbine are switched capacitors. Although the manufacturer equipped the wind turbine with only 400 $\mathrm{kVAR}$ of reactive power compensation, the wind turbine we considered is equipped with an additional 1.5 MVAR reactive power compensation. The wind turbine is compensated at different levels of compensation depending on the level of generation. The capacitor is represented by the capacitance $\mathrm{C}$. In series with the capacitance, is the parasitic resistance $\left(R_{c}\right)$, representing the losses in the capacitor. This resistor is usually very small for a good quality capacitor.

4) Induction Generator

The induction generator $(1.5 \mathrm{MW}, 480 \mathrm{~V}, 60 \mathrm{~Hz})$ used for this wind turbine can be represented as the per phase equivalent circuit shown. Figure 8 shows the equivalent circuit of the induction generator. The operating slip of the generator at fundamental frequency $(60 \mathrm{~Hz})$ is around $1 \%$. The slip of induction generator at harmonic frequency can be computed as:

$$
S_{h}=\frac{h \omega_{s}-\omega_{r}}{h \omega_{s}}
$$

where

$\mathrm{S}_{\mathrm{h}}=$ slip for $\mathrm{h}^{\text {th }}$ harmonics

$\mathrm{h}=$ harmonics order

$\omega_{\mathrm{s}}=$ synchronous speed of the generator

$\omega_{\mathrm{r}}=$ rotor speed of the generator 
Thus for higher harmonics ( $5^{\text {th }}$ and higher) the slip is close to one $\left(S_{h}=1\right)$ and for practical purposes is assumed to be one. From the circuit diagram we can compute the impedance seen by the harmonic source as:

$$
\mathrm{Z}(\mathrm{C}, \mathrm{h})=\left(\mathrm{Z}_{\text {line }}+0.5 \mathrm{Z}_{\mathrm{xfmr}}\right) / /\left(0.5 \mathrm{Z}_{\mathrm{xfmr}}+\mathrm{Z}_{\mathrm{C}} / / \mathrm{Z}_{\text {gen }}\right)
$$

The admittance can be found from the impedance.

$$
\mathrm{Y}(\mathrm{C}, \mathrm{h})=\frac{1}{\mathrm{Z}(\mathrm{C}, \mathrm{h})}
$$

The admittance corresponds to the harmonic current for a given harmonic voltage excitation. In this section, we analyze the system admittance from the most dominant harmonic frequency (up to $23^{\text {rd }}$ harmonics, excluding even and non-triplen harmonics) and vary the size of the capacitor compensation. Because the data in the field only consists of the total harmonic distortion, and does not provide information about individual harmonics, we

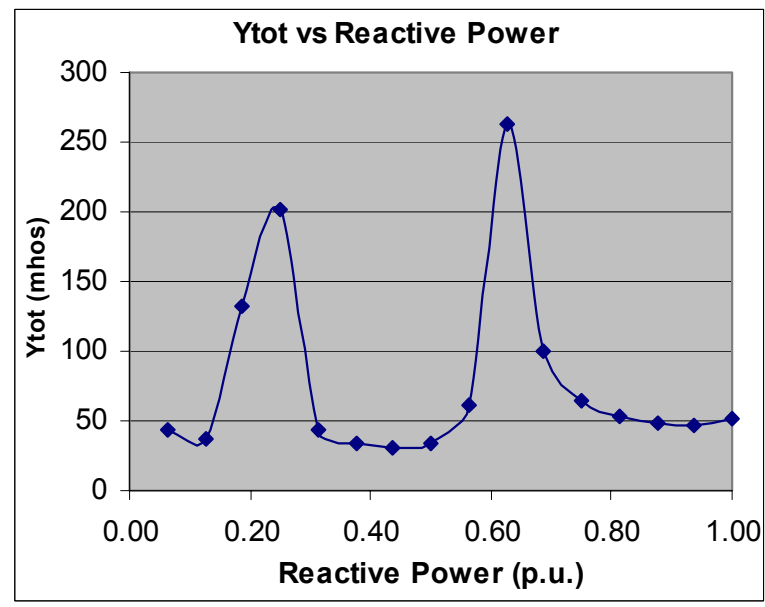

Fig. 11a. The total admittance for higher harmonics (odd and nontriplen) as a function of reactive compensation.

\section{PU VAR Support on a MW Class WT Near \\ Full Generation Magnitude of VAR}

Support, 0.95 PF Leading at Rated KW

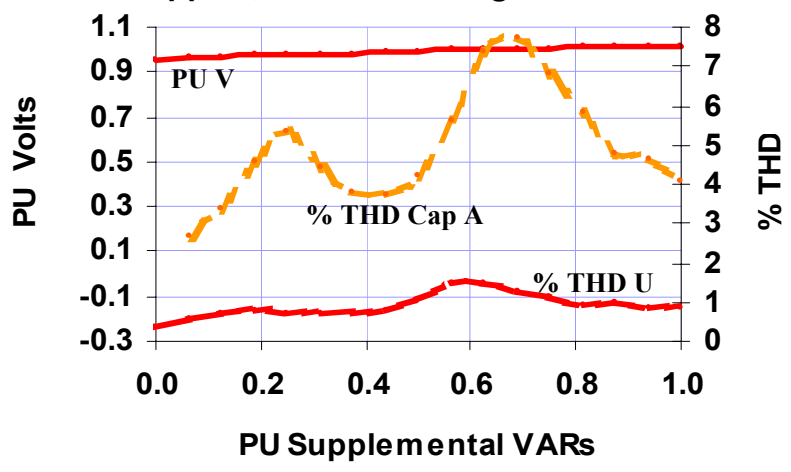

Figure 11b. Total harmonic distortion of the current as a function of the reactive compensation in per unit.

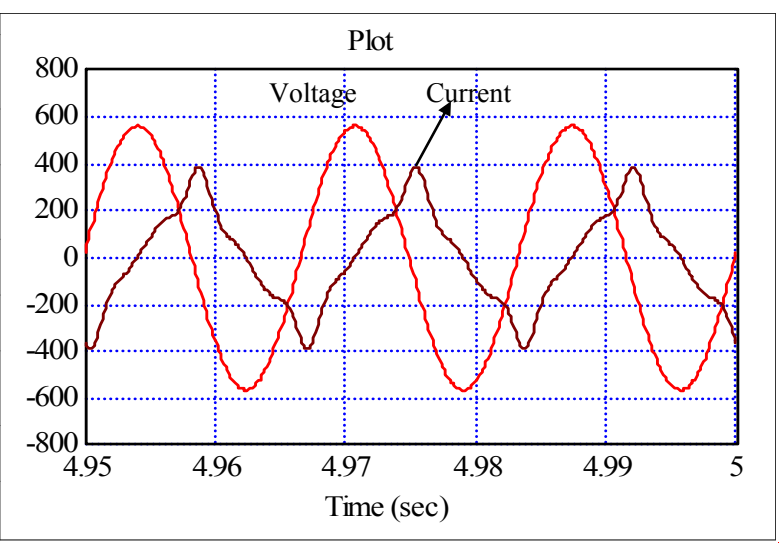

Fig.12. The voltage and current of a transformer under light load condition.

can only compare the trends shown by the admittance. Figure 11a shows that the total admittance computed for all higher harmonics of interest up to $23^{\text {rd }}$ harmonics (odd and non-triplen harmonics) is plotted as a function of the total reactive power (per unit) as the size of switched capacitors varied. For a comparison, the measured data of the total harmonic distortion as a function of the total reactive power (per unit) is presented in Figure 11b. Both Figures 11a and 11b show that when the size of the capacitor compensation is increased, the circuit admittance (in Figure 11a) or the total harmonic distortion (in Figure 11b) shows resonance at different higher harmonics. The two graphs show the same trend. There are two values of capacitances that amplify the total harmonic distortions revealed from the calculation and from the field measurement. Although the magnitudes do not match completely, the size of reactive power at which the two resonance frequencies occur shows a good correlation between the field measurement and the calculated values.

From Figure 11, we can say that the circuit will resonate at different higher harmonics when that particular harmonics presents or excites the circuit. The source of harmonics can be traced back from the saturation level of the magnetizing branch of the transformer, creating a nonlinear magnetizing inductance and a distorted line current. Figure 12 shows distorted current as a result of the transformer operating in a saturation condition. Note that the deviation of the line current from sinusoidal wave shape may excite the harmonics circuit created by the combination of line inductances and capacitance of the capacitor compensation in the collector system network.

\section{CONCLUSION}

This paper describes various aspects of power quality within the wind power plant. There are many others that 
could be included in this paper such as flicker, faults, start-up transients etc., but, because of the space limit, those topics are not included in this paper.

In general, the voltage at each turbine within the wind power plant varies independently because of the difference in wind speeds, the line impedances, and compensations among the wind turbines. However, the most important point is the point of interconnection that provides a gateway for the wind power plant to the real world. In this paper, we have shown that the reactive power compensation, strategically placed, affects the voltage behavior of a very large area consisting of many wind power plants. We also show that when studying a large wind power plant, we cannot represent the plant as a single turbine. A very large wind power plant should be represented by groups of wind turbines representing its unique characteristics with respect to the location, the type of turbines, the control setting, and the line impedance. Finally, we show that capacitor compensation used by induction generators in a wind power plant can lead to self-excitation and harmonics.

\section{ACKNOWLEDGMENT}

We acknowledge the support of the U.S. Department of Energy, Oak Creek Energy, and Southern California Edison.

\section{REFERENCES}

[1] Muljadi, E.; Butterfield, C.P.; Yinger, R.; Romanowitz, H.; "Energy Storage and Reactive Power Compensator in a Large Wind Farm," $A$ Collection of the 2004 ASME Wind Energy Symposium Technical Papers Presented at the $42^{\text {nd }}$ AIAA Aerospace Sciences Meeting and Exhibit, Reno, NV, January 5-8, 2004.

[2] Muljadi, E.; Butterfield, C.; Gevorgian, V.; "The Impact of the Output Power Fluctuation of a Wind Farm on a Power Grid," Conference Record, Third International Workshop on Transmission Networks for Offshore Wind Farms, Royal Institute of Technology, Stockholm, Sweden, April 11 - 12, 2002.

[3] IEC Standard 61400-21 Measurement and Assessment of Power Quality of Grid Connected Wind Turbines.

[4] Timothy J.E. Miller, Editor, "Reactive Power Control in Electric Systems" John Wiley \& Sons, 1982.

[5] Mathur, R.M., Editor, "Static Compensators for Reactive Power Control", Cantext Publications, Winnipeg, Canada, 1984.

[6] Muljadi, E.; Butterfield, C.P.; Romanowitz, H.; Yinger, R.; "SelfExcitation and Harmonics in Wind Power Generation," Transactions of ASME, Journal of Solar Energy Engineering, November 2005, Vol. 127, pp. 581-587. 


\section{REPORT DOCUMENTATION PAGE}

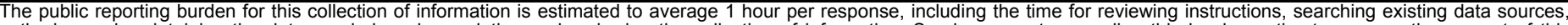

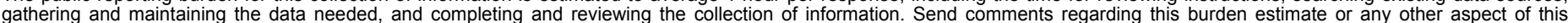

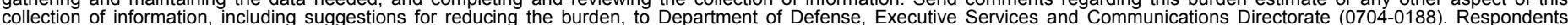

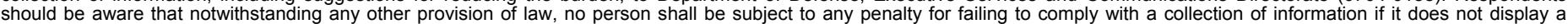

should be aware that notwithstand

PLEASE DO NOT RETURN YOUR FORM TO THE ABOVE ORGANIZATION.

\begin{tabular}{l|l|l|l} 
1. REPORT DATE $(D D-M M-Y Y Y Y)$ & 2. & REPORT TYPE & 3. DATES COVERED (FrOm - TO)
\end{tabular} January 2006

Conference paper

4. TITLE AND SUBTITLE

Power Quality Aspects in a Wind Power Plant: Preprint 5a. CONTRACT NUMBER

DE-AC36-99-GO10337

5b. GRANT NUMBER

5c. PROGRAM ELEMENT NUMBER

5d. PROJECT NUMBER

NREL/CP-500-39183

5e. TASK NUMBER

WER6.2112

5f. WORK UNIT NUMBER
7. PERFORMING ORGANIZATION NAME(S) AND ADDRESS(ES)

National Renewable Energy Laboratory

1617 Cole Blvd.

Golden, CO 80401-3393
8. PERFORMING ORGANIZATION REPORT NUMBER

NREL/CP-500-39183

9. SPONSORING/MONITORING AGENCY NAME(S) AND ADDRESS(ES)

10. SPONSOR/MONITOR'S ACRONYM(S) NREL

11. SPONSORING/MONITORING AGENCY REPORT NUMBER

12. DISTRIBUTION AVAILABILITY STATEMENT

National Technical Information Service

U.S. Department of Commerce

5285 Port Royal Road

Springfield, VA 22161

13. SUPPLEMENTARY NOTES

14. ABSTRACT (Maximum 200 Words)

Although many operational aspects affect wind power plant operation, this paper focuses on power quality. Because a wind power plant is connected to the grid, it is very important to understand the sources of disturbances that affect the power quality.

\section{SUBJECT TERMS}

wind turbine; wind farm; wind power plant; power quality; wind energy; aggregation; power systems; renewable energy; reactive power compensation; self-excitation; harmonics

\begin{tabular}{|c|c|c|c|c|}
\hline \multicolumn{3}{|c|}{ 16. SECURITY CLASSIFICATION OF: } & \multirow{2}{*}{$\begin{array}{l}\text { 17. LIMITATION } \\
\text { OF ABSTRACT } \\
\text { UL }\end{array}$} & \multirow{2}{*}{$\begin{array}{ll}\text { 18. } & \text { NUMBER } \\
\text { OF PAGES }\end{array}$} \\
\hline $\begin{array}{l}\text { a. REPORT } \\
\text { Unclassified }\end{array}$ & $\begin{array}{l}\text { b. ABSTRACT } \\
\text { Unclassified }\end{array}$ & $\begin{array}{l}\text { c. THIS PAGE } \\
\text { Unclassified }\end{array}$ & & \\
\hline
\end{tabular}

19a. NAME OF RESPONSIBLE PERSON

19b. TELEPHONE NUMBER (Include area code) 